\title{
Chromosomes and Phylogeny in Some Genera of the Crepidinae By
}

\author{
E. B. Babcock, G. L. Stebbins, Jr., and J. A. Jenkins \\ Division of Genetics, University of California, Berkeley, Calif.
}

\section{Introduction}

The cyto-genetic and taxonomic studies of Crepis, which have now been carried on for sixteen years, have amply demonstrated the value of this genus for such studies (Babcock and Navashin, 1930, Hollingshead and Babcock, 1930, Babcock and Cameron, 1934). In order to gain a better understanding of the origin and relationships of Crepis, and of the evolutionary processes in the subtribe Crepidinae as a whole, a study of the various other genera of this subtribe has been undertaken. This paper is intended as a preliminary report on this work, and presents the results obtained to date on the genera most nearly related to Crepis, and which have been studied sufficiently so that conclusions concerning them can be drawn.

Of the six genera included in this report, only two, Lactuca and Ixeris, have been previously examined cytologically to any extent. Ishikawa (1921) reported on the meiotic chromosomes of both of these genera, and obtained cytological evidence that Ixeris should be recognized as distinct. Marchal (1920) recorded, without illustrations, the haploid number $\mathrm{n}=8$ in Lactuca perennis and L. virosa, counts that have proved erroneous (see below), while Gates and Rees (1921) made a careful study of meiosis in $L$. Scariola and $L$. sativa, obtaining the haploid number $\mathrm{n}=9$ for these two species and L. muralis. In addition, the chromosome number of Lactuca (as Mulgedium) tuberosa has been counted by Poddubnaja-Arnoldi (ex Tischler 1936), of Ixeris dentata by Okabe (1932), of I. (as Lactuca) denticulata by Heitz (1929), of Youngia (as Crepis) japonica by Tahara (1910) and Hollingshead and Babcock (1930), of $Y$ (as Lactuca) depressa and of Dubyaea hispida (as Crepis bhotanica) by Babcock and Cameron (1934). A significant cytogenetic study within this group is that of Ono and Sato (1935) on Ixeris (Crepidiastrum) lanceolata var. latifolia $\times 1$. (Paraixeris) denticulata.

\section{Acknowledgment}

To the following the writers are particularly indebted for the receipt of seeds and roots of many species: Mr. C. C. Deam, Mr. C. 
H. Knowlton, Dr. S. F. Blake, Dr. R. Pampanini, Dr. H. H. Hu, Prof. Dr. W. Robyns, Dr. N. Shimotomai, Dr. S. Okabe.

To others who have generously sent material of various species, and to the directors of the numerous botanical gardens who have generously sent seeds of many species, we also wish to express our gratitude. We are also much indebted to Mr. Ernest Jund for valuable assistance in growing the cultures and in making the cytological preparations, and to the Park Naturalist, Yosemite National Park, and his assistants for their generous cooperation in germinating the seeds of the more difficult species.

\section{Materials and Methods}

Chromosome counts and morphological studies were made exclusively on somatic root tip metaphases. The root tips were fixed when the rosettes were growing vigorously in six inch pots in the greenhouse. Two fixatives were used: (1) Müntzing's (1932) modification of Navashin's chrom-acetic-formalin solution followed by the glycerin-butyl dehydration and embedding schedule, (2) Randolph's (1935) modification of chrom-acetic-formalin ("Craf") and embedded in paraffin according to his schedule.

Sections were cut from 10-12 $\mu$ and stained with either Smith's (1934) modification of crystal violet or with Stockwell's (1934) modification of Flemming's triple stain. The latter gave much better preparations, particularly in those species where there were many cytoplasmic inclusions.

The morphological studies of the chromosomes were complicated by the fact that the chromosomes in most of the species examined were quite long and twisted so that it was difficult, particularly in those with high numbers, to find plates in which they were well separated, and almost impossible to find plates in which all of them were in one plane. In addition there was some variability in the absolute length of the chromosomes, even in neighboring plates in the same section, though there was no indication that the relative length of the two arms of any chromosome was materially changed.

Plates were selected for drawing primarily because they were well spread and as "flat" as possible. Satellites were a secondary consideration, though an attempt was made to illustrate the total number found in any one species.

All drawings were made with the aid of a camera lucida using a Zeiss apochromat $90 \times$, N.A. 1.3 objective and a Zeiss $30 \times$ compensating ocular, which gave a magnification of 5000 times at table level, and was reduced one-half in publication. This magnification is the same as that used in the previous papers on Crepis. 
Table 1. Chromosome Numbers in Six Genera of Crepidinae

Note: Species listed in italics are here reported for the first time. Published counts verified by the writers are indicated with an!

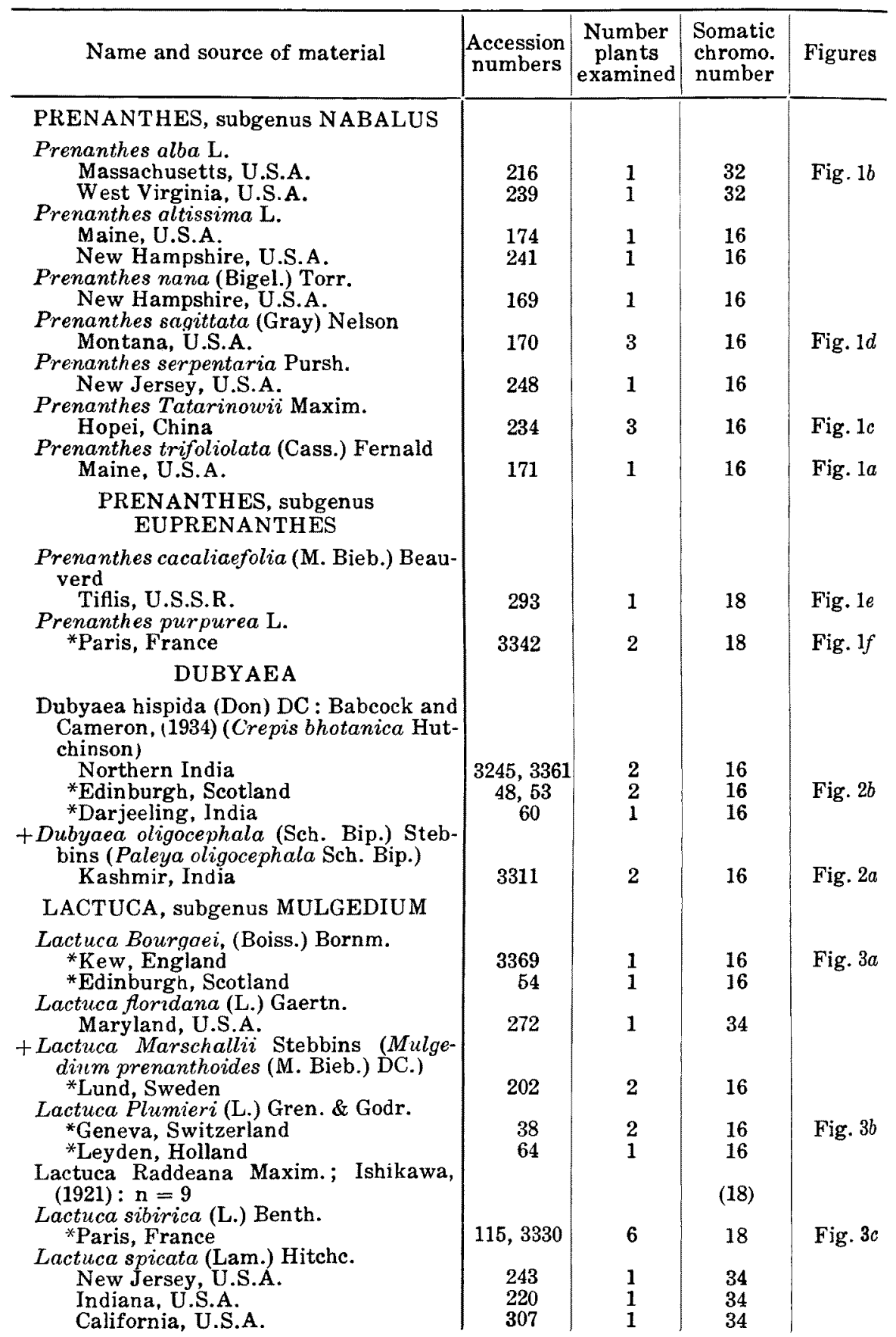


Table 1. (Continued)

\begin{tabular}{|c|c|c|c|c|}
\hline Name and source of material & $\begin{array}{c}\text { Accession } \\
\text { numbers }\end{array}$ & $\begin{array}{c}\text { Number } \\
\text { plants } \\
\text { examined }\end{array}$ & $\begin{array}{l}\text { Somatic } \\
\text { chromo. } \\
\text { number }\end{array}$ & Figures \\
\hline $\begin{array}{l}\text { Lactuca tatarica (L.) C.A. Mey. } \\
\text { Cap D'Antibes, France }\end{array}$ & 164 & 1 & 18 & \\
\hline $\begin{array}{l}\text { Lactuca villosa Jacq. } \\
\text { Virginia, U.S.A. }\end{array}$ & 271 & & & \\
\hline Maryland, U.S.A. & 273 & $\begin{array}{l}1 \\
1\end{array}$ & 34 & \\
\hline Louisiana, U.S.A. & 290 & 1 & 34 & \\
\hline LACTUCA, subgenus SORORIA & & & & \\
\hline $\begin{array}{l}\text { Lactuca rostrata (Blume) Boerl. } \\
\text { Mt. Gedeh, Java }\end{array}$ & 233 & 1 & 18 & Fig. $3 d$ \\
\hline LACTUCA, subgenus LACTUCOPSIS & & & & \\
\hline $\begin{array}{c}+ \text { Lactuca aurea (Sch. Bip.) Stebbins } \\
\text { (Mulgedium sonch folium Vis.) }\end{array}$ & & & & \\
\hline & 308 & 1 & 16 & \\
\hline $\begin{array}{l}\text { *Edinburgh, Scotland } \\
\text { Lactuca Schulzeana Büttner }\end{array}$ & 49 & 1 & 16 & Fig. $3 e$ \\
\hline $\begin{array}{l}\text { Dalatando, Angola, tropical Africa } \\
\text { Lactuca Haımanniana, Aschers. }\end{array}$ & 279 & 2 & 16 & Fig. $3 f$ \\
\hline Cirenaica, North Africa & 74 & 1 & 16 & \\
\hline LACTUCA, subgenus MYCELIS & & & & \\
\hline $\begin{array}{l}\text { Lactuca muralis (L.) Fresen.: Gates and } \\
\quad \text { Rees }(1921): n=9\end{array}$ & & & & \\
\hline $\begin{array}{l}\text { *Copenhagen, Denmark } \\
\text { Hohenstein, Germany }\end{array}$ & $\begin{array}{l}103 \\
178\end{array}$ & $\begin{array}{l}1 \\
1\end{array}$ & $\begin{array}{r}18 \\
8\end{array}$ & \\
\hline *Lund, Sweden & 200 & 1 & 18 & Fig. $4 b$ \\
\hline LACTUCA, subgenus PHAENIXOPUS & & & & \\
\hline $\begin{array}{l}\text { Lactuca orientalis Boiss. } \\
\text { Gümüsh-Khaneh, Turkey } \\
\text { Lactuca viminea (L.) J. \& C. Presl. }\end{array}$ & 3314 & 3 & 36 & \\
\hline $\begin{array}{l}\text { Güüsh-Khaneh, Turkey } \\
\text { *Paris, France }\end{array}$ & $\begin{array}{l}3316 \\
3335\end{array}$ & $\begin{array}{l}3 \\
6\end{array}$ & $\begin{array}{l}18 \\
18\end{array}$ & Fig. $4 a$ \\
\hline LACTUCA, subgenus SCARIOLA & & & & \\
\hline $\begin{array}{l}\text { Lactuca campestris Greene } \\
\text { Indiana, U.S.A. } \\
\text { Lactuca canadensis L. }\end{array}$ & 226 & 1 & 34 & \\
\hline $\begin{array}{l}\text { Lactuca canadensis L. } \\
\text { var, typica Wiegand } \\
\text { Ohio, U.S.A. }\end{array}$ & 179 & 1 & 34 & \\
\hline $\begin{array}{l}\text { var. integrifolia (Bigel.) Wiegand } \\
\text { Maine, U.S.A. }\end{array}$ & 214 & 1 & 34 & \\
\hline $\begin{array}{l}\text { var. latifolia O.F. Ktze } \\
\text { Vermont, U.S.A. }\end{array}$ & 212 & 1 & 34 & \\
\hline $\begin{array}{l}\text { Massachusetts, U.S.A. } \\
\text { var, obovata Wiegand }\end{array}$ & 211 & 1 & 34 & \\
\hline $\begin{array}{l}\text { var. obovata Wiegand } \\
\text { Indiana, U.S.A. }\end{array}$ & 221 & 1 & 34 & \\
\hline $\begin{array}{l}\text { Ohio, U.S.A. } \\
\text { Lactuca cretica, Desf. }\end{array}$ & 181 & 1 & 34 & \\
\hline $\begin{array}{l}\text { Cirenaica, North Africa } \\
\text { Lebanon, Syria }\end{array}$ & $\begin{array}{r}75 \\
262\end{array}$ & 1 & $\begin{array}{l}16 \\
16\end{array}$ & Fig. $4 d$ \\
\hline $\begin{array}{l}\text { Lactuca graminif lia Michx. } \\
\text { Florida, U.S.A. }\end{array}$ & 3379 & 2 & 34 & Fig. $4 g$ \\
\hline $\begin{array}{l}\text { Lactuca indica } \mathrm{L} \text {. } \\
\text { China }\end{array}$ & 373 & 1 & 18 & \\
\hline $\begin{array}{l}\text { Lactuca laciniata (Houtt.) Makino: Ishi- } \\
\text { kawa, (1921): } n=9 \\
\text { Peiping, China }\end{array}$ & 235 & 1 & 18 & Fig. $4 h$ \\
\hline
\end{tabular}


Table 1. (Continued)

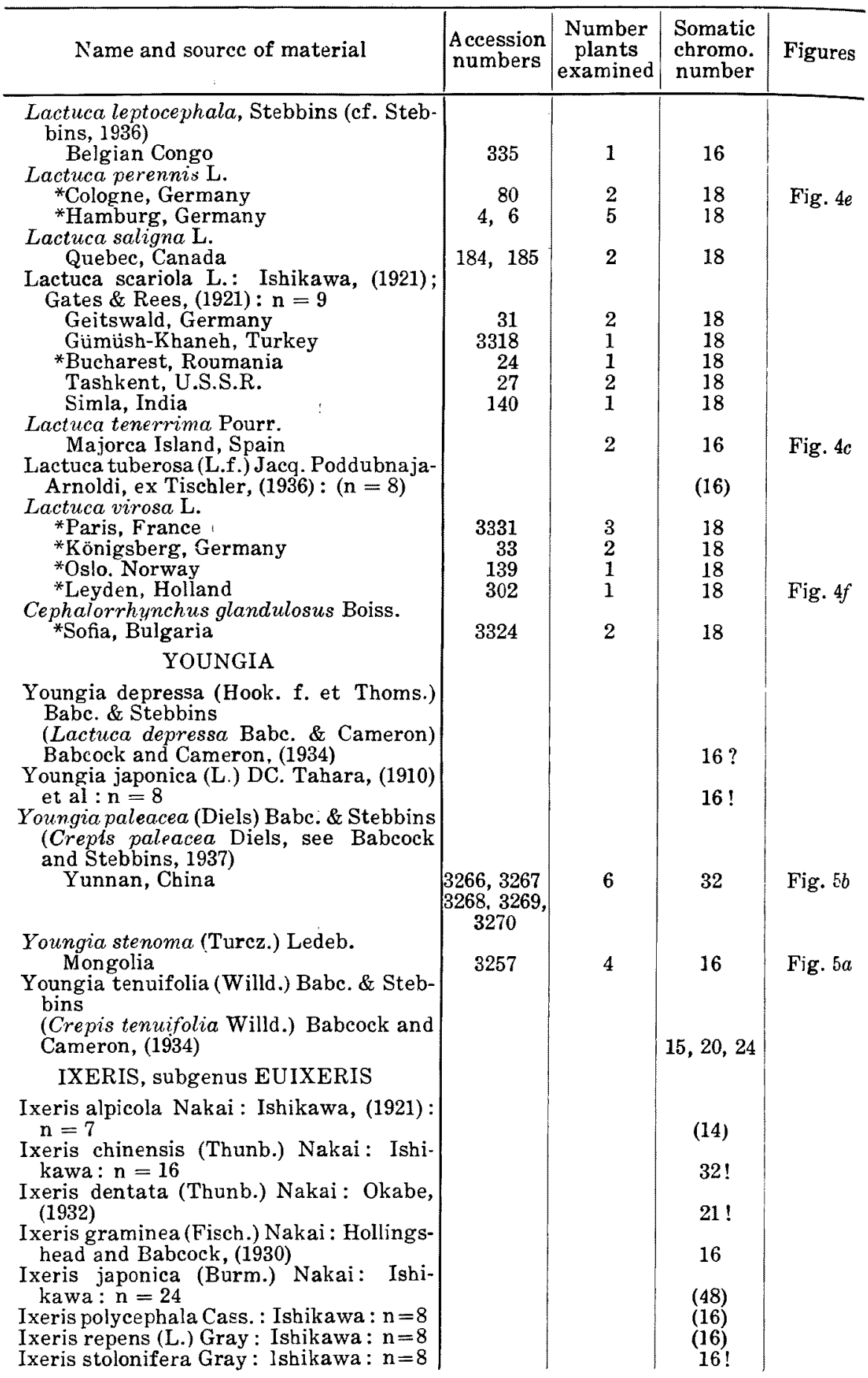


Table 1. (Continued)

\begin{tabular}{|c|c|c|c|c|}
\hline Name and source of material & $\begin{array}{l}\text { Accession } \\
\text { numbers }\end{array}$ & $\begin{array}{c}\text { Number } \\
\text { plants } \\
\text { examined }\end{array}$ & $\begin{array}{l}\text { Somatic } \\
\text { chromo. } \\
\text { number }\end{array}$ & Figures \\
\hline $\begin{array}{l}\text { IXERIS, subgenus PARAIXERIS } \\
\text { +Ixeris chelidoniifolia (Makino) Stebbins } \\
\text { Ishikawa: } \mathrm{n}=5 \\
\text { + Ixeris denticulata (Houtt.) Stebbins } \\
\text { + subsp. typica (Maxim.) Stebbins (Lac- } \\
\text { tuca denticulata (Houtt.) Maxim.): } \\
\text { Ishikawa: }=5 \text {, Heitz, (1929) } \\
\text { + subsp. ramosissima (Benth.) Stebbins } \\
\text { Hong Kong, China } \\
\text { +subsp. sonchifolia (Bunge) Stebbins } \\
\text { Peiping, China } \\
\text { IXERIS, subgenus CREPIDIASTRUM } \\
\text { +Ixeris Keiskeana (Maxim.) Stebbins } \\
\text { lshikawa (1921): } \mathrm{n}=5 \\
\text { +Ixeris lanceolata subsp. platyphylla (Ma- } \\
\text { kino) Stebbins } \\
\text { (Crepidiastrum lanceolatum var. lati- } \\
\text { folium Nakai) } \\
\quad \text { Ishikawa, (1921); Ono \& Satô, (1935) } \\
\text { n=5 } \\
\text { +Ixeris linguaefolia Gray } \\
\text { (Crepidiastrum linguaefolium Nakai) } \\
\text { Bonin Islands, Japan }\end{array}$ & $\begin{array}{l}194 \\
237\end{array}$ & $\begin{array}{l}3 \\
3\end{array}$ & $\begin{array}{l}10 ! \\
10 \\
10\end{array}$ & $\begin{array}{l}\text { Fig. } 5 c \\
\text { Fig. } 5 d\end{array}$ \\
\hline
\end{tabular}

\section{Description}

Nine out of thirty-five species, representing both subgenera of Prenanthes, have been examined. The species $P$. alba $(2 \mathrm{n}=32$, Fig. $1 b), P$. altissima $(2 \mathrm{n}=16), P$ nana $(2 \mathrm{n}=16), P$ sagittata $(2 \mathrm{n}=16$, Fig. $1 d), P$. serpentaria $(2 \mathrm{n}=16), P$. Tatarinowii $(2 \mathrm{n}=$ 16, Fig. $1 c)$, and $P$ trifoliolata $(2 \mathrm{n}=16$, Fig. $1 a)$ are all on the basis of eight, whereas $P$. cacaliaefolia $(2 \mathrm{n}=18$, Fig. $1 e)$ and $P$ purpurea $(2 \mathrm{n}=18$, Fig. $1 f)$ in the subgenus Euprenanthes are on the basis of nine.

The chromosome morphology of these species is strikingly similar. All of the chromosomes within any specific genom are very much alike in shape and size, having median or submedian constrictions. The only morphological difference between the various genoms is in the absolute size of the chromosomes. The chromosomes of $P$. cacaliaefolia are definitely larger than those of Nabalus, though they have the same relative proportions. The species within the subgenus Nabalus itself show very little difference in size.

Dubyaea oligocephala $(2 \mathrm{n}=16$, Fig. $2 a)$ and $D$. hispida $(2 \mathrm{n}=16$, Fig. $2 b)$ have very similar genoms both in size and morphology, all of the chromosomes having median or submedian 


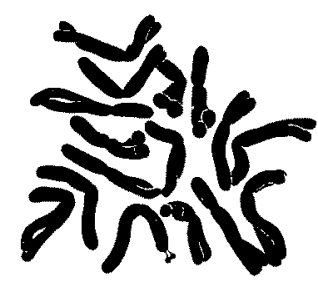

a P. trifoliolata

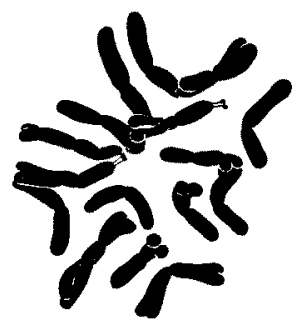

d P. sagittata

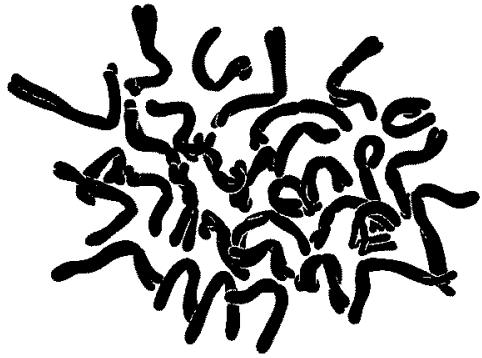

b P. alba

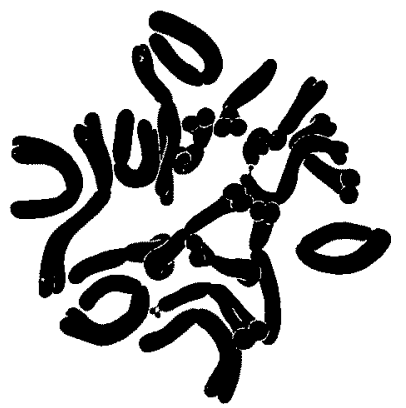

e P. cacaliaefolia

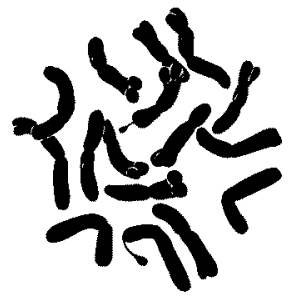

c P. Tatarinowii

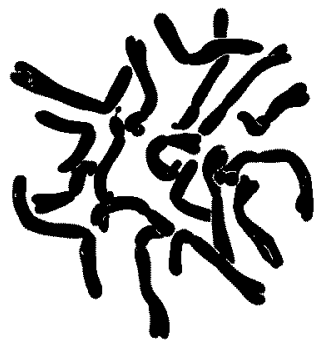

f P. purpurea

Fig. 1. Chromosomes of Prenanthes.

constrictions. The idiograms of both species are strikingly similar to those in the subgenus Nabalus of Prenanthes.

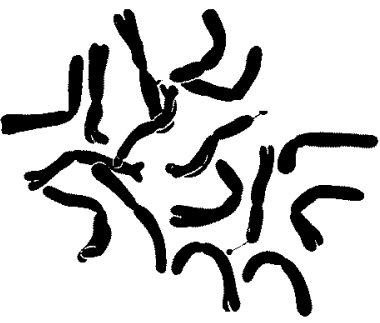

a D. oligocephala

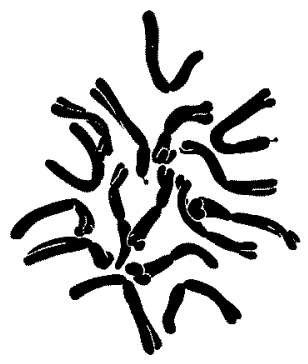

b D. hispida

Fig. 2. Chromosomes of Dubyaea.

In Lactuca, 30 ouc of about 150 species, representing all but one of the subgenera, have been studied. The subgenus Mulgedium, ${ }^{1)}$ exclusive of the American species, has the two basic numbers eight and nine. The species with eight as a basic number, namely: L. Bourgaei $(2 \mathrm{n}=16$, Fig. $3 a)$, Lactuca Marschallii $(2 \mathrm{n}=16)$, and L. Plumieri $(2 \mathrm{n}=16$, Fig. $3 b)$ all have a similar idiogram. One pair has an almost median constriction and the remainder are definitely sub-terminal, grading off to a small pair with a round head. L. sibirica $(2 \mathrm{n}=18$, Fig. $3 c)$ and $L$. tatarica $(2 n=18)$ both have essentially the same idiogram which differs from

1) This subgenus is recognized in the same sense as the ganus of Cassini, i.e., to include all of those species in which the involucre is well imbricated, and the achene is unbeaked or has a short, stout beak. 
the eight-paired species in the addition of a small pair of medianly constricted chromosomes. There is some variation in the absolute size of the chromosomes within this subgenus, but it is not marked.

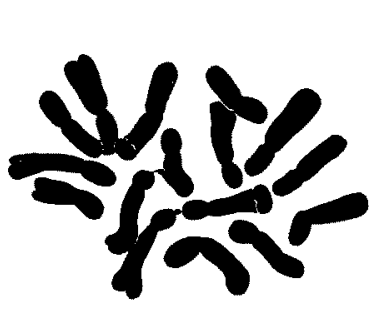

a L. Bourgaei

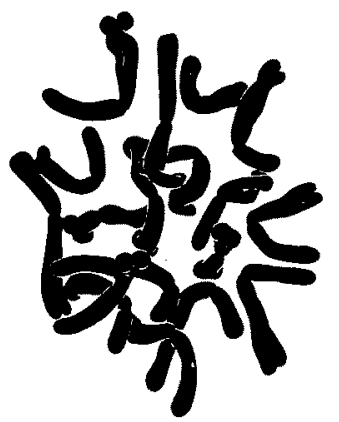

d L. rostrata

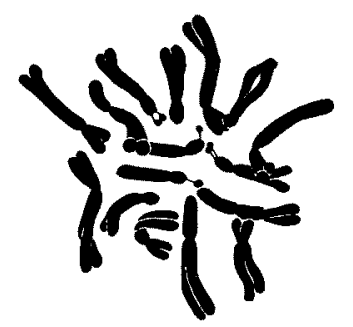

b L. Plumieri

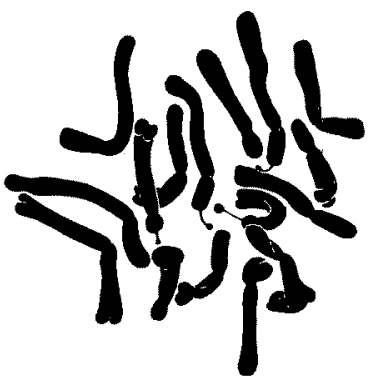

e L. bracteata
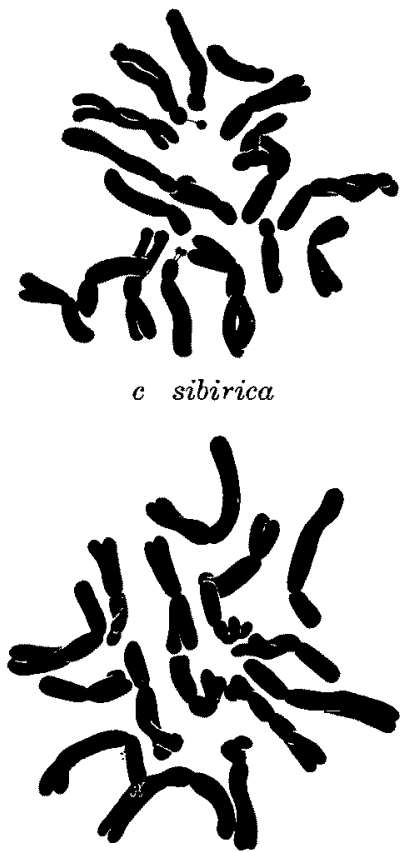

$f$ L. Schulzeana

Fig. 3. Chromosomes of Lactuca, subgenera: Mulgedium, Sororia and Lactucopsis.

L. rostrata $(2 \mathrm{n}=18$, Fig. $3 d)$ is the only species in the subgenus Sororia examined. The chromosome morphology is quite distinct from that in the subgenus Mulgedium in that all of the chromosomes have median or sub-median constrictions. There is a very close resemblance between the chromosomes of $L$. rostrata and those in the subgenus Euprenanthes in number, morphology and size. The absolute size of the chromosomes in L. rostrata is somewhat greater than in the species of the subgenus Mulgedium.

Four species: L. aurea $(2 \mathrm{n}=16)$, L. bracteata $(2 \mathrm{n}=16$, Fig. $3 e)$, L. Haimanniana $(2 \mathrm{n}=16)$, L. Schulzeana $(2 \mathrm{n}=16$, Fig. $3 f)$ in the subgenus Lactucopsis are on the basis of eight. The chromosomes are somewhat larger, but on the whole very similar to those of the sixteen chromosome species in the subgenus Mulgedium, the only obvious difference being that two pairs rather than one have sub-median constrictions.

L. muralis $(2 \mathrm{n}=18$, Fig. $4 b)$ and L. viminea $(2 \mathrm{n}=18$, Fig. $4 a)$, the type species of the subgenera Mycelis and Phaenixopus, both have idiograms very similar to $L$. sibirica, except that the absolute size of 
the chromosomes is markedly reduced. The chromosomes of $L$. orientalis $(2 \mathrm{n}=36)$ are not so much reduced in size, though they too have mostly subterminal constrictions and a few small chromosomes with sub-median constrictions.

Leaving out of the discussion for the time being the American species, L. campestris, L. canadensis, and L. graminifolia, the subgenus Scariola has the two basic numbers eight and nine. There is considerable morphological variation in the nine series. $L$. laciniata $(2 \mathrm{n}=18$, Fig. $4 h)$, and $L$. indica $(2 \mathrm{n}=18)$, have the largest chromosomes of any species of this subgenus, and a high proportion with submedian constrictions. L. Scariola $(2 \mathrm{n}=18), L$. virosa $(2 \mathrm{n}=18$, Fig. $4 f)$ and L. saligna $(2 \mathrm{n}=18)$ have a very similar genom to that of $L$. sibirica, i. e., mostly sub-terminal chromosomes

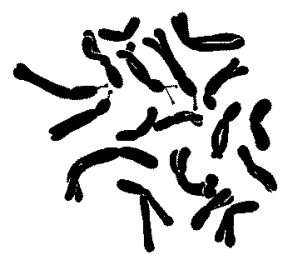

a L. viminea

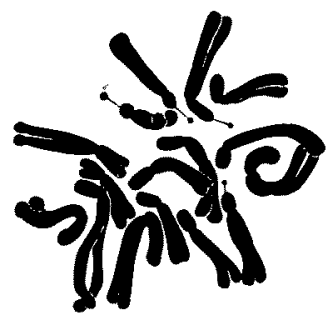

d L. cretica

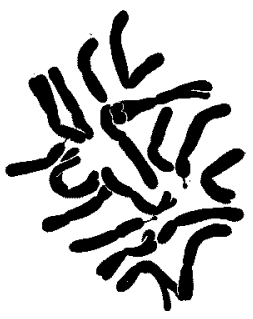

b L. muralis

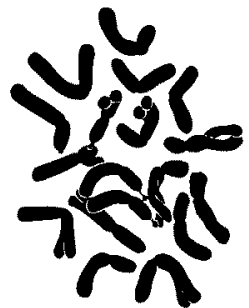

e L. perennis

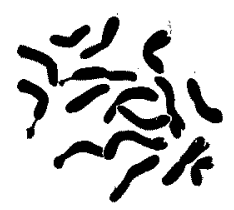

c L. tenerrima
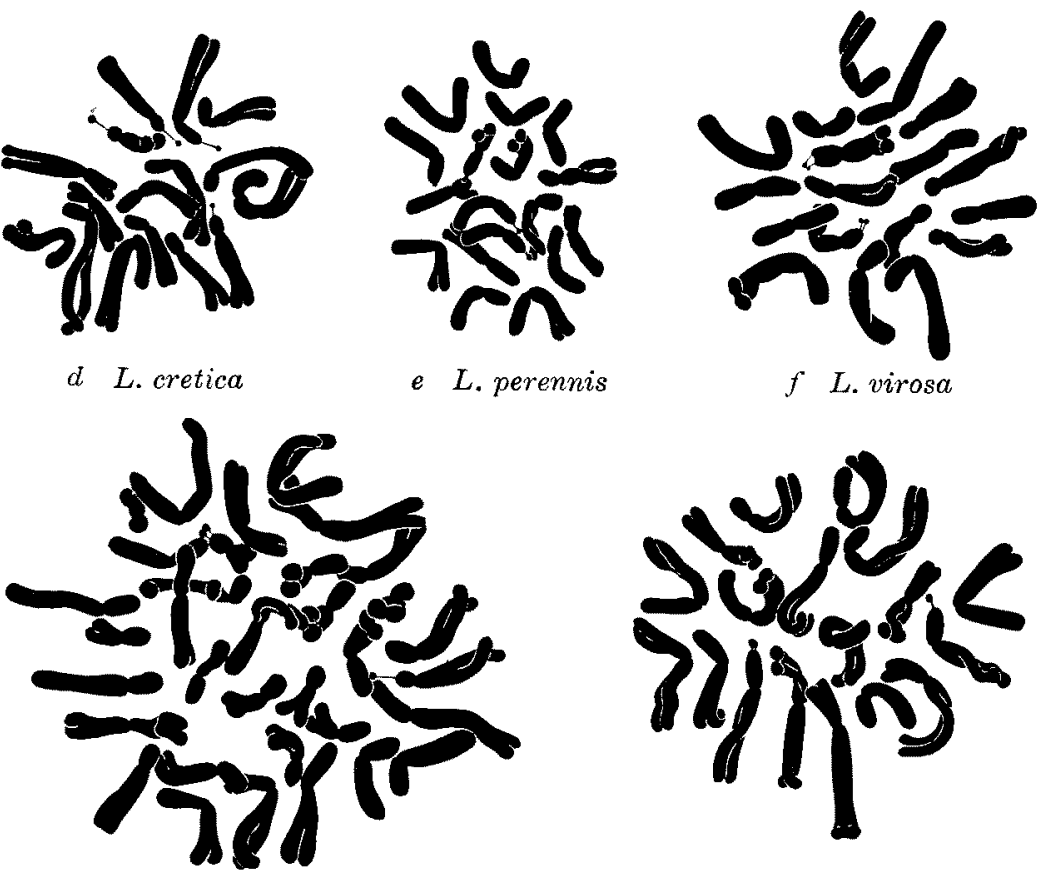

f L. virosa

g L. graminifolia

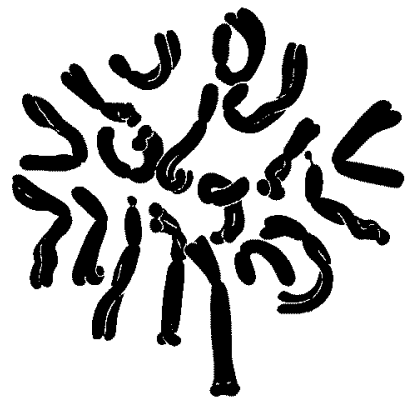

h L. laciniata

Fig. 4. Chromosomes of Lactuca, subgenera: Phaenixopus, Mycelis and Scariola. 
with one large almost submedian pair and a small pair of medianly constricted chromosomes. L. perennis $(2 \mathrm{n}=18$, Fig. $4 e)$ has smaller chromosomes than any of the nine-paired species of Scariola, and at the same time has more medianly constricted chromosomes. It also lacks the small pair of medianly constricted chromosomes characteristic of the Scariola-virosa group.

Of the species in the subgenus Scariola with eight as a basic number, $L$. cretica $(2 \mathrm{n}=16$, Fig. $4 d)$ has a similar idiogram to $L$. Plumieri of the subgenus Mulgedium, $i$. e., the chromosomes are decidedly subterminal with one pair almost submedian. The other two species examined, L. tenerrima $(2 \mathrm{n}=16$, Fig. $4 c)$ and L. leptocephala $(2 \mathrm{n}=16)$ are very exceptional in that they have very small chromosomes of which it is difficult to determine the morphology. Their idiograms are strikingly different from any others in the genus.

The American species of Lactuca, namely $L$. floridana $(2 \mathrm{n}=34)$, L. spicata $(2 \mathrm{n}=34), \quad L$. villosa $(2 \mathrm{n}=34)$, of the subgenus Mulgedium, and L. campestris $(2 \mathrm{n}=34), L$. canadensis $(2 \mathrm{n}=34)$, and L. graminifolia $(2 \mathrm{n}=34$, Fig. $4 g)$ of the subgenus Scariola, are all quite similar in chromosome morphology and chromosome size. In each species there are a few pairs of submedianly constricted chromosomes, but the majority are subterminally constricted. There is considerable variation in size between the chromosomes within any specific genom. Although Ishikawa (1921) recorded the haploid number $\mathrm{n}=9$ for $L$. villosa, it is doubtful from the results of the present study that his plant was of this American species.

Cephalorrhynchus glandulosus $(2 \mathrm{n}=18)$ differs morphologically from Lactuca chiefly in the anomalous character of its achenes, which are very little flattened and are five-sided, and resembles such species of Lactuca as L. sibirica and L. virosa in both the number and the morphology of its chromosomes. The material available was not satisfactory for illustration.

In Youngia, cytological study has been possible on only four or five species. The count previously reported by Babcock and Cameron (4) for Youngia (as Lactuca) depressa is somewhat doubtful. The plants grown from seed received from Ghose and Co., Darjeeling, India, as Crepis depressa did not flower and their rosette leaves were quite different in appearance from those of herbarium specimens of $Y$. depressa. $Y$. stenoma $(2 \mathrm{n}=16, \mathrm{Fig} .5 a)$ is very similar in both chromosome number and morphology to the species of Dubyaea and of Prenanthes subgenus Nabalus, $i$.e., the chromosomes are medianly or submedianly constricted and are all very much alike. $Y$. paleacea $(2 \mathrm{n}=32$, Fig. $5 b)$ is a tetraploid, based on a haploid set similar to that of $Y$. japonica (Hollingshead and Babcock 
1930, fig. $23 c$ ), except that the chromosomes are considerably larger.

Several species of Ixeris have been studied by Ishikawa (1921), as Lactuca, and the chromosome numbers of the following have been

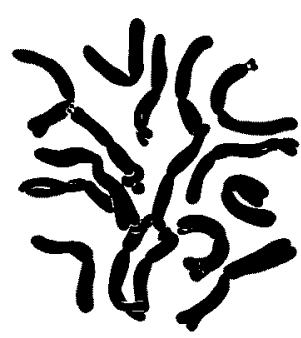

a Y. stenoma

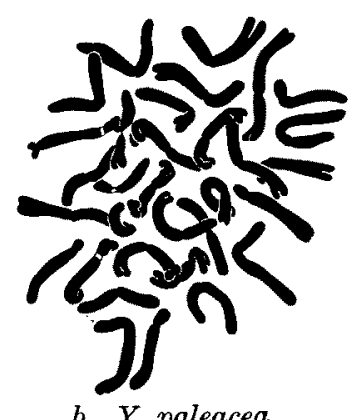

b Y. paleacea

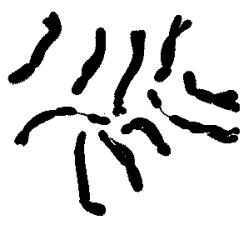

c I. denticulata subsp. ramosissima

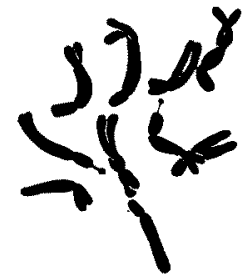

d I. denticulata subsp. sonchifolia

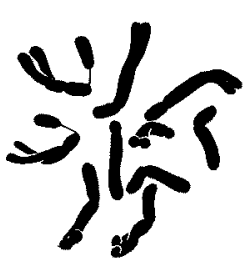

e I. linguaefolia confirmed by the present writers: I. chinensis, $I$. dentata, I. denticulata subsp. typica, I. stolonifera. In the chart, Fig. 6, the names Ixeris graminea and I. polycephala are used as the correct synonyms for those species listed by Ishikawa as $L$. tamagawensis, and $L$. Matsumurae respectively. (See Kitamura, 1935). Of the additional three forms listed in the table, two, I. linguaefolia $(2 \mathrm{n}=10$, Fig. $5 e)$, and 1 . denticulata subsp. ramosissima $(2 n=10$, Fig. $5 c)$, agree with the other members of their subgenera in both the number and the morphology of their chromosomes. The genom of subsp. sonchifolia $(2 \mathrm{n}=10$, Fig. $5 d)$ although otherwise identical with that of the other subspecies of $I$. denticulata, includes a pair of normal sized satellites, rather than the large ones characteristic of the other subspecies.

\section{Discussion}

\section{Phylogeny and chromosome number}

The phylogenetic principles on the basis of which the position and relationships of the various genera and subgenera have been determined will be discussed elsewhere, but they are in general similar to those employed in the Crepis work. The relative position of the groups is illustrated in the accompanying chart (Fig. 6). In it the basic haploid numbers of the various genera are given after their names, and the species contained in each subgenus are listed within the smaller squares. With the exception of Youngia, in which the arrangement follows that in our monograph of the genus (Babcock 


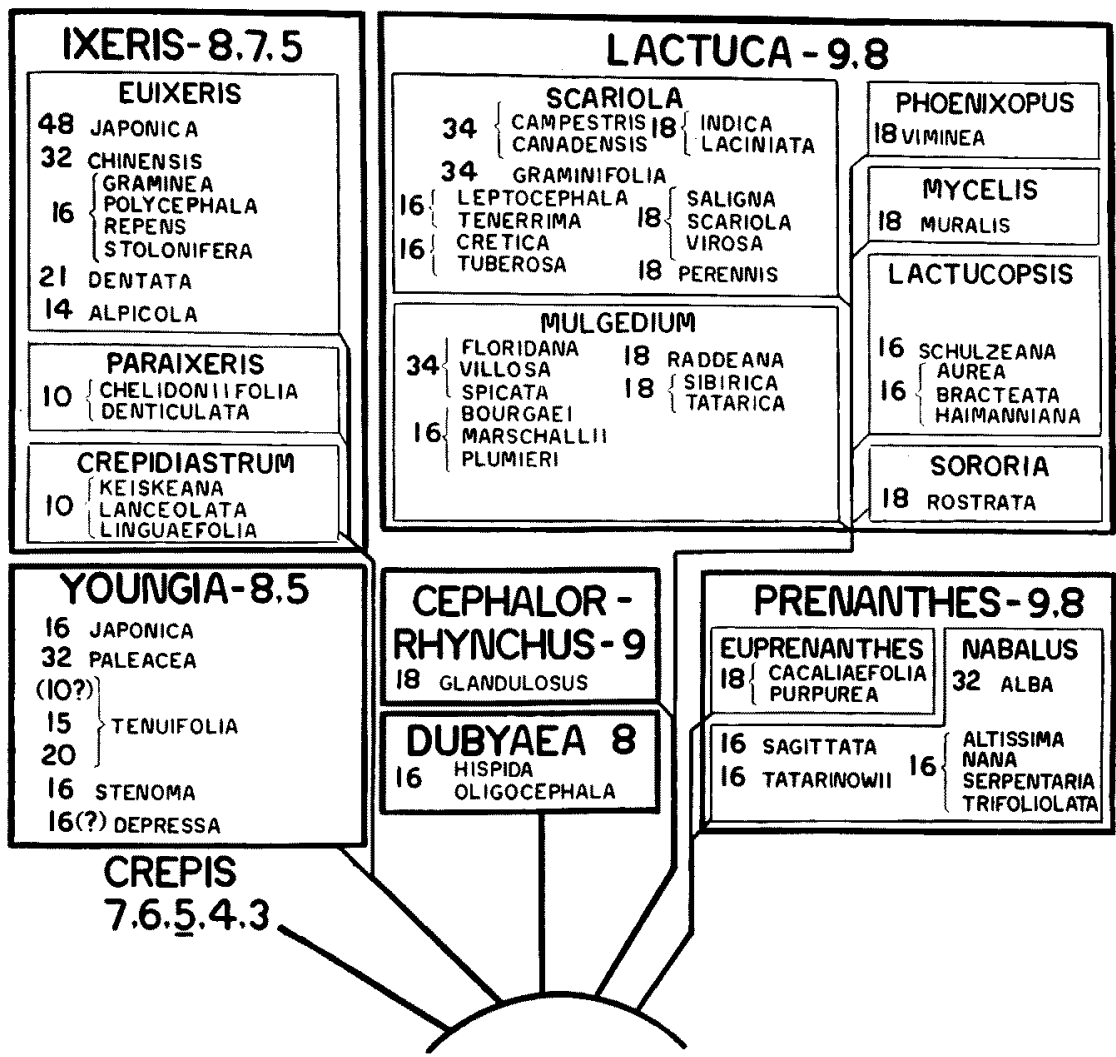

Fig. 6. Phylogenetic relationships of and the known chromosome numbers within the genera Dubyaea, Prenanthes, Cephalorrhynchus, Lactuca, Ixeris, and Youngia, and their subgenera.

and Stebbins, 1937), the species within the squares have not been arranged phylogenetically since their interrelationships are as yet incompletely known, but those closely related taxonomically and with the same chromosome number have been bracketed together, and their somatic number given outside the bracket. A slight departure from the natural order is made in the case of Youngia, which, in order to conserve space, has been placed underneath rather than beside Ixeris.

A glance at this chart shows that the haploid numbers 8 and 9 are the most common in this group of genera. It is further evident that neither of these two numbers is definitely the more primitive. Both are found in the two primitive genera, and both occur in the most advanced subgenus of Lactuca. An analysis of the chromosome number and phylogenetic relationships within each genus and subgenus is therefore presented in order to determine as far as possible the relationship between the two basic numbers. 
Dubyaea. The fact that both of the species examined of this most primitive genus have the basic number $n=8$, suggests that this is the original basic number for the group as a whole. The cytological evidence supports the separation of these two species from Crepis, (Stebbins, 1937) as they are cytologically much nearer to Prenanthes subgenus Nabalus, and to some species of the subgenus Mulgedium of Lactuca than to any species of Crepis.

Prenanthes. The evidence from this genus supports that from Dubyaea, since the more primitive subgenus, Nabalus, has the haploid number 8, and the more advanced Euprenanthes has 9. The inclusion of $P$. cacaliaefolia in the same subgenus with $P$. purpurea, on the basis of the character of its involucral bracts, pappus, and achenes, is well supported by the cytological evidence.

Lactuca. This genus shows the greatest variation of any here studied in the degree of morphological specialization of its members. Although the haploid numbers 8 and 9 occur with about equal frequency, not only in the genus as a whole but in each of the larger subgenera as well, regardless of their phylogenetic position, within each subgenus there is some indication that the 8-paired condition is the more primitive. Among the 8-paired series there is a larger proportion of perennials, and of species with relatively few-headed inflorescences and large floral parts, while the types most highly specialized in the development of their inflorescences and in the reduction in number and size of their floral parts (L. viminea, L. muralis) as well as those species which show their recent origin by their aggressive, "weedy" tendencies ( $L$. Scariola, L. saligna), all belong to the 9-paired series. Nevertheless, since the number 9 occurs among the more primitive species, and the transition from 8 to 9 has not yet been traced in any well defined phylogenetic sequence, there is a definite possibility that both numbers are original (the assumption of some degree of polyphylesis in the origin of this polymorphic genus does not seem improbable to the writers), and that in the later evolution of the genus the 9-paired species have been more successful than those with 8 pairs.

The consistent presence of the haploid number 17 in the American species of Lactuca is a remarkable situation, in view of the practical absence of polyploidy among the Old World species of the genus. The most logical assumption is that they are amphidiploids, and they are most probably descended from hybrids between 8- and 9-paired species. This hypothesis is quite compatible with the fact that representatives of both the subgenera Mulgedium and Scariola are included in this group, since 9- and 8-paired species occur in both subgenera, but suggests that the hybridization and 
doubling must have occurred more than once. This suggestion is further supported by the distribution of the various Old World species to which the American ones are related. L. spicata, L. villosa, and L. floridana find their nearest relatives among the 8-paired species in L. Marschallii, L. Bourgaei, and other species of the Caucasus region and Asia Minor, while among the 9-paired species their nearest relative is L. Raddeana of eastern Asia. L. graminifolia, however, is most closely related to $L$. capensis and other African species, as well as to $L$. tenerrima of Spain, while $L$. canadensis, and $L$. campestris are nearest to $L$. formosana Maxim. of Eastern Asia, as well as to $L$. indica and L. laciniata. The conclusion is inescapable, therefore, that the diploid ancestors of the American species came to the New World from various parts of the Old, probably over different routes of migration. Since this is the case, the apparent absence of diploid species in this country is difficult to explain. One explanation is offered by the known behavior of a recently evolved amphidiploid species, Spartina Townsendii (Huskins, 1931) which has crowded out its diploid ancestors in the regions in which it occurs. That the polyploid American Lactucas could have done the same is amply demonstrated by their present behavior. L. spicata has much the widest range of any species of the subgenus Mulgedium, except for L. sibirica and L. tatarica, which belong to a different section of the subgenus, and is an aggressive, weedy species, very abundant in the recently glaciated areas of eastern North America. On the other hand, its Old World relatives are all relatively restricted in range, and are for the most part uncommon in the regions where they do occur, showing little or no tendency to spread. L. canadensis is, like L. spicata, a weedy type, although its old World relatives are also widespread and common.

The polyploid nature of these American species of Lactuca affords a striking parallel to the situation in Crepis, in which genus the American species are likewise, with the exception of $C$. nana and C. elegans, all amphidiploids (Hollingshead and Babcock, 1931). Both cases confirm the postulate of Sax (1936), that polyploidy is most prevalent near the periphery of the range of a genus.

Youngia. The presence of the haploid number 8 in four of the five species of this genus that have been investigated, as well as the close resemblance between the chromosomes of $Y$. stenoma (Fig. $5 a$ ) and the two species of Dubyaea (Fig. 2) suggest that this genus has been differentiated from Dubyaea or its ancestors without much cytological change. Taxonomic evidence also supports this hypothesis for the origin of Youngia (cf. Babcock and Stebbins, 1937). The different basic number in $Y$. tenuifolia is as yet unexplained. In both 
chromosome number and morphology, this species is nearer to Crepis than to the other species of Youngia, and as it is also somewhat intermediate taxonomically, the suggestion has been made that it arose through hybridization at a time when the differentiation of the two genera was less marked than at present (Babcock and Stebbins, 1937).

Ixeris. This genus has the basic haploid number 8 in half of the species studied. Since these species resemble Youngia in their chromosome morphology (cf. Hollingshead and Babcock, 1930, Fig. $23 a$ and $c$ ), as well as in their external appearance and their geographic distribution, the logical hypothesis seems to be that the two groups have had a common origin from an 8-paired stock close to Dubyaea. A drawback to this hypothesis is that these 8-paired species of the subgenus Euixeris are the most advanced in the genus, and the 7-paired I. alpicola, as well as the 5-paired species of the subgenera Paraixeris and Crepidiastrum are in general more primitive in habit, floral characteristics, and distribution.

In the case of I. alpicola as well as $I$. dentata, which is apparently a polyploid derivative of the former (Okabe, 1932), a possible explanation is at hand. I. alpicola is quite similar in habit to the 7paired species of Crepis, particularly $C$. elegans, and in floral characteristics the two species are not radically different, except that $C$. elegans has terete achenes with slender ribs, as is characteristic of Crepis, while Ixeris alpicola has somewhat compressed, strongly. ribbed, subalate achenes, typical of Ixeris. Both species are alpine or subalpine in habitat. Since no other species of the Crepidinae, or at least none even remotely connected with this group, has the basic number seven, it is quite probable that the morphological and cytological resemblance between Crepis flexuosa, C. elegans, and C. nana to Ixeris alpicola indicates an actual relationship, and therefore a transition from Ixeris to Crepis.

The evidence from the phylogenetic position of both groups suggests that this transition is the result of intergeneric hybridization when the two genera were in a formative stage, a suggestion compatible with the chromosome number and morphology of the two groups. Furthermore this is more satisfactory from the point of view of their present geographic distribution than the hypothesis that the group represents the link through which Ixeris has been derived from Crepis, or vice versa.

The relationships of the 5-paired Ixeris species are equally difficult to understand. The hypothesis that they are the progenitors of the 8-paired Euixeris species is unlikely in view of the apparent connection between the latter and Youngia or Dubyaea. A genetic 
connection with 5-paired Crepis species is unlikely on taxonomic grounds, as well as on the basis of their chromosome morphology, which is definitely Ixeris-like. An hypothesis concerning their origin will be presented below.

The presence of the same number and a similar morphology of the chromosomes in Ixeris denticulata subsp. sonchifolia as in subsp. typica does not support Nakai's (1920) opinion that this is a good species of the genus Ixeris, sensu strictu, and is cytological evidence for the merging of Ixeris and Paraixeris, as was done by one of us on taxonomic grounds (Stebbins, 1937). The bearing of the experiments of Ono and Satô (1935) on the relationships between the subgenera Paraixeris and Crepidiastrum has been discussed elsewhere (Stebbins, 1937).

\section{Relationship of the group to Crepis}

Since the primitive basic chromosome number for this group of genera is apparently $n=8$, the relationship of this to the primitive number $\mathrm{n}=5$ in Crepis is of considerable importance to the phylogeny of the group. An hypothesis to explain the relationship between these numbers has already been presented by the senior author (Babcock, 1936 pp. 48-50), who suggested that the numbers 18 and 16 are the result of hybridization and amphidiploidy. The present work has produced some evidence in favor of this hypothesis, and some against it. These points may be summarized as follows:

1. The presence of two pairs of satellited chromosomes in Dubyaea oligocephala (Fig. 2a) removes the difficulty suggested by the senior author $(1936$, p. 50$)$, and increases the possibility of amphiplasty as an explanation of the situation in the species which have only one satellited pair.

2. The interrelationships of the subgenera of Ixeris are most easily explained on this hypothesis. Crepidiastrum and Paraixeris could be considered primitive types in which the amphidiploidy had not taken place, while the Euixeris species could be thought of as resulting from crossing between these and the ancestors of Youngia, in which amphidiploidy had not yet taken place.

Against the hypothesis are the following points:

1. The primitive nature of both Dubyaea and Prenanthes requires that their 4-paired ancestors be more primitive and much older than any 4-paired species of Crepis, or of any other genus of the Cichorieae whose number is now known.

2. The greater frequency of the haploid number 8 among these species does not agree with expectation, since in Crepis 5-paired species are in general more primitive than those with 4 pairs, and hence 9-paired species, presumably originating by doubling of 5 and 
4, should be more primitive than those with 8 pairs. This difficulty could, however, be overcome by assuming that the 9-paired species have become more successful in evolution, and hence have produced more advanced types, which have crowded out their primitive ancestors.

3. Except for the presence of two pairs of satellited chromosomes in Dubyaea oligocephala, the chromosome complement of that genus, as well as of Prenanthes and the more primitive species of Lactuca and Youngia, does not resemble a Crepis complement duplicated. There is a much higher proportion of medianly constricted chromosomes in these than there is in Crepis. This discrepancy could be accounted for in two ways:

A. The original ancestors of Dubyaea, Prenanthes, and Lactuca may have had a large proportion of subterminally constricted chromosomes, which have acquired median constrictions through translocations. This is improbable, first because of the great similarity in chromosome morphology of such distantly related species as Youngia stenoma, Dubyaea oligocephala, and Prenanthes trifoliolata, a fact which indicates that slight rather than great structural changes have taken place in the evolution of these species from their common ancestors; and second, because the evolutionary tendency in Lactuca has been from median toward subterminal constrictions, as is pointed out below, and hence the evolution of the original Lactuca complement from that of its ancestors would have to be of just the reverse type from that which can be traced within the genus, a course which seems rather improbable.

B. The common ancestors of Dubyaea, Prenanthes, and Crepis may have had 4 or 5 pairs of medianly constricted chromosomes, which became subterminally constricted through translocations in the stock which evolved toward Crepis, and remained in their original condition in the amphidiploid stock which produced the other genera. The likelihood of this explanation rests on the discovery of species of the Cichorieae which are more primitive than any of these here considered, and which have four or five pairs of medianly constricted chromosomes, or on the postulate that a series of such species formerly existed, but are now extinct. Hence, until such species are discovered, the amphidiploid origin for these 9- and 8-paired species must remain hypothetical.

An alternative hypothesis suggests itself in the light of the evidence presented in this paper. The haploid number 8 may be the most primitive one for the subtribe Crepidinae, and the lower numbers derived from it by a gradual process of reduction. This process has evidently taken place in the more advanced species of Crepis 
(Hollingshead and Babcock, 1930), and in the Gramineae (Avdulov, 1931), Polygonaceae (Jaretzky, 1928), Cruciferae (Manton, 1932), and other groups, while evidence of one way in which it could take place has been presented by Navashin and Gerassimova (1935). If this were true, then the other primitive species of the Cichorieae should share with Dubyaea and Prenanthes the numbers 16 and 18. In particular, species of the subtribe Leontodontinae should be found with 8 or 9 pairs of chromosomes. In this subtribe, which is characterized by a pappus more primitive than that of the Crepidinae, three genera are known to contain 5- or 4-paired species, i.e., Leontodon, Picris (Bergman, 1935), and Hypochaeris (unpublished counts of the writers). Hence a more complete survey of chromosome number and morphology in the Cichorieae as a whole should throw definite light on the probability of either one of these alternative hypotheses.

\section{Chromosome size and phylogeny}

The reduction in chromosome size with advancing evolution was first postulated by Delaunay (1926) and was noted in Crepis by the senior author (Babcock and Cameron, 1934). In the present material there are several cases which parallel those already known in Crepis:

(1) The three primitive subgenera of Lactuca; Mulgedium, Sororia, and Lactucopsis, have, on the average, definitely larger chromosomes than the more specialized subgenera; Mycelis, Phaenixopus, and Scariola.

(2) L. muralis, which has small flower-heads and large panicles, and is definitely specialized, has strikingly smaller chromosomes than the species of Lactucopsis from which it is probably derived.

(3) L. tenerrima and L. leptocephala, both with very small chromosomes, are relatively reduced and specialized as compared to their relatives with larger chromosomes, $L$. perennis, $L$. tuberosa and L. cretica.

(4) Youngia stenoma and $Y$. depressa (at least the plant grown as this species) both have relatively large chromosomes and both belong to the primitive sections of the genus (Babcock and Stebbins, 1937). Y. paleacea is intermediate in both chromosome size and phylogenetic position. Y. japonica, with the smallest chromosomes (Hollingshead and Babcock, 1930, Fig. 23c) is the most advanced species of this genus.

(5) Ixeris dentata and $I$. alpicola, the most primitive species of the subgenus Euixeris, have large chromosomes, while the specialized, reduced species such as I. graminea, I. polycephala and I. stolonifera have very small chromosomes.

However, there are certain apparent exceptions to this hypothesis : 
(1) Prenanthes cacaliaefolia is more advanced, but has definitely larger chromosomes than the species of Nabalus and of the primitive genus Dubyaea.

(2) L. rostrata, although its achenes are relatively unspecialized, has large panicles of small, few-flowered heads and specialized calyculate involucres along with the largest chromosomes yet known in Lactuca.

These exceptions may indicate that phylogenetic increase in size occasionally takes place in the Crepidinae, although as yet no hypothesis concerning it can be formed without a more detailed cytological study of those species which form the connecting links between the ones here mentioned and other subgenera of Lactuca and Prenanthes.

Increase in chromosome size with advancing evolution has been postulated by Avdulov (1931) for the Gramineae, and connected by him with a progressive cooling of the climate during the evolution of those species with large chromosomes. This connection cannot, however, be applied to the species of Prenanthes and Lactuca here in question. Prenanthes cacaliaefolia grows under climatic conditions quite similar to those in the regions inhabited by the members of the subgenus Nabalus, while Lactuca rostrata is one of the few species of its genus found in the tropics. Of the other two tropical species of Lactuca which have been studied, one, L. leptocephala, has small chromosomes and the other, L. Schulzeana, large ones, so that in Lactuca and Prenanthes there is apparently no significant correlation between chromosome size and geographic distribution.

\section{Chromosome morphology and phylogeny}

The fact that taxonomic relationship is usually accompanied by similarity in chromosome morphology has been amply demonstrated in Crepis (Hollingshead and Babcock, 1930, Babcock and Cameron, 1934), Allium (Levan, 1935), and other genera. Therefore a study of the chromosome morphology of a group of related species should throw light not only on their connections to each other, but also on the type of changes in chromosome morphology that occur with advancing evolution. Such a study in the group here under consideration has led to the following observations:

1. Among the more primitive species there is a striking similarity in both the size and morphology of the chromosomes, even where they belong to different genera, while among those more advanced, there may be considerable differences even within the same subgenus. Thus the complements of the two species of Dubyaea, of the two primitive species of Youngia, and of all the species of Prenanthes, subgenus Nabalus, are essentially similar, while there are considerable differences in Lactuca within a single subgenus, such as 
Scariola. Although, as is very evident from the study of genera in which translocations are common, such as Datura (Blakeslee, 1932), Oenothera, and others, similarity in external morphology of the chromosome complement does not necessarily mean structural similarity, nevertheless the uniformity among the primitive species of this group of the Crepidinae suggests that less structural differentiation of the chromosomes has occurred in the differentiation of the primitive species of this group than in the more advanced ones. This suggests that in the relatively primitive groups of the Crepidinae the differentiation of genera has been accompanied by fewer changes in the gross morphology and structure of the chromosomes than has accompanied the evolution of individual species or species groups in the more advanced, larger and more diversified genera.

2. The hypothesis of Levitzky (1931), also suggested by Levan (1935), that primitive types tend to have chromosome sets of which the members are all of about the same size, and which all possess median, or nearly median constrictions, and that with advancing evolution the chromosomes become more unequal in size, and tend to become subterminally constricted, is well supported by the present study. All of the primitive subgenera of this group have chromosome complements primitive in this respect, with the exception of the subgenera Crepidiastrum and Paraixeris of Ixeris, and Mulgedium in Lactuca. On the other hand, such specialized species as L. muralis and $L$. viminea have not only considerable inequality in size among their chromosomes, but possess a considerable proportion of subterminally constricted chromosomes. Within the most advanced subgenus, Scariola, L. perennis retains a relatively primitive genom (Fig. 4e), along with primitive characteristics of external morphology. L. cretica, a somewhat xerophytic species with specialized tuberous roots and unusually long filiform beaks $2-3$ times the length of its achenes, has predominantly subterminally constricted chromosomes (Fig. 4d), while the three modern, weedy species, L. Scariola, $L$. virosa, and L. saligna, all have chromosomes very unequal in size, and with a majority of subterminal or submedian constrictions.

A striking contrast to this correlation is afforded by Crepis, in which the hypothesis of Levitzky holds only to a very limited extent. For instance, $C$. conyzaefolia, a primitive species of the subgenus Catonia, has a complement very similar to that of C. myriocephala and other highly specialized species of the subgenus Barkhausia (Babcock and Cameron, 1934, Figs. 7 and 17). This difference between Crepis and these other genera of the Crepidinae may be explained on Levan's hypothesis, that this change from median to subterminal constrictions is the result of unequal translocation. If all 
of the chromosomes of a set are equal in size and medianly constricted, as in Dubyaea, Nabalus, and Youngia, any unequal translocation must produce greater inequality and fewer median constrictions, while if the chromosomes are very unequal in size and all are subterminally constricted, unequal translocations can produce an equalization in size, and medianly constricted chromosomes; or if confined to the long arms, will have relatively little effect. These facts have been demonstrated by the experiments of Levan (1935) and Navashin and Gerassimova (1935). Levan, working with two species of Allium whose chromosomes were nearly equal in size and had mostly median constrictions, found that the majority of the translocations obtained resulted in chromosomes of unequal size and with more subterminal constrictions. Navashin and Gerassimova found that new chromosomes produced by translocation in Crepis capillaris and $C$. tectorum, species with mostly subterminally constricted chromosomes, were most often medianly constricted, and homozygous races produced in this manner by Gerassimova (1935), would, on Levitzky's hypothesis, be considered more primitive than the original tectorum stock.

On this basis, the prevalent genom of Crepis must be considered to have more altered chromosomes than those of Dubyaea and Prenanthes, an hypothesis in keeping with the relatively advanced phylogenetic position of Crepis in relation to these other two genera. In this regard, it is perhaps significant that three of the most primitive species of Crepis, C. sibirica, C. paludosa, and C. albida, have a greater proportion of medianly constricted chromosomes than almost all of the others (Babcock and Cameron, 1934, Figs. 6 and 16).

An objection to Levan's hypothesis is found in the observation of Navashin and Gerassimova (1935), that small chromosomes and short arms of chromosomes act most often as recipients of translocations produced in Crepis by aging of seeds, and hence a progressively greater inequality in the size of the chromosomes and chromosome arms might not be attained by this method. The hypothesis of Levitzky (1931), that the inequality is evolved by the progressive accumulation of deficiencies, has as yet no evidence to support it, and the facts presented in the present paper provide no method of judging the validity of either hypothesis.

\section{Summary and Conclusions}

1. The chromosome numbers of nine species of Prenanthes, twenty-five of Lactuca, two each of Dubyaea and Youngia, one of Cephalorrhynchus, and two subspecies and a variety of Ixeris are here reported for the first time. 
2. The somatic numbers 16 and 32 are found in Prenanthes, subgenus Nabalus, 18 in the subgenus Euprenanthes, 16 in the genus Dubyaea, 16, 18, 34 and 36 in the various subgenera of Lactuca, 18 in Cephalorrhynchus, and 16 in the species of Youngia reported in this paper.

3. 16 is probably the more primitive diploid number in Prenanthes, Dubyaea and Youngia. In Lactuca more of the primitive species have this number, while more of the advanced species have 18 chromosomes, but the two numbers may both have existed since the formation of the genus.

4. The American species of Lactuca here studied are amphidiploids with the somatic number 34 . They are probably derived from crossing between 16 and 18 chromosome species, with subsequent doubling of the chromosome complement. This hybridization and doubling must have occurred more than once.

5. The chromosome number and morphology of the Chinese subspecies of Ixeris denticulata supports the taxonomic evidence that the genera Ixeris and Paraixeris should be merged.

6. The hypothesis of an amphidiploid origin for the numbers 16 and 18 in these genera is possible only if species of the Cichorieae are found with a somatic complement of 8 or 10 mostly medianly constricted chromosomes, or the existence of a series of such species in the past is assumed. An alternative to this hypothesis is that 16 and 18 are primitive numbers for the Crepidinae, and 10 and 8 are derived from them by reduction.

7. The hypothesis that reduction in absolute size of the chromosomes often accompanies evolutionary advancement is borne out by the study of these genera, although exceptions are found in Prenanthes, subgenus Euprenanthes, and Lactuca, subgenus Sororia.

8. The hypothesis that primitive species have many chromosomes with median constrictions, and have the chromosomes of a set nearly equal in size, and that with advancing evolution subterminal constrictions are evolved and the chromosomes of a set become un equal in size is borne out by this study. It is further suggested that in this group the original differentiation of genera was accompanied by less structural alteration of the chromosomes than was the evolution of species groups among the more highly evolved and diversified subgenera.

\section{Literature Cited}

Avdulov, N. P. 1931. Karyo-systematische Untersuchungen der Familie Gramineen. Bull. Appl. Bot., Suppt. 44: 428 pp.

Babcock, E. B. 1936. The origin of Crepis and related genera with particular reference to distribution and chromosome relationships. Essays in Geobotany in honor of William Albert Setchell : 9-53.

and Navashin, M. 1930. The genus Crepis. Bibliographia Genetica 6: 1-90. 
Babcock, E. B. and Cameron, D. 1934. Chromosomes and phylogeny in Crepis II. The relationships of one hundred eight species. Univ. Calif. Publ. Agr. Sci. $6: 287-324$.

- and Stebbins, G. L. Jr., 1937. A monograph of the genus Youngia. Publ. No. 484, Carnegie Inst. Wash. (in press).

Bergman, B. 1935. Zytologische Studien über die Fortpflanzung bei den Gattungen Loontodon and Picris. Svensk. Bot. Tidskr. 29: 155-301.

Blakeslee, A. F. 1932. The species problem in Datura. Proc. Sixth Int. Cong. Genetics 1 : 104-120.

Delaunay, L. 1926. Phylogenetische Chromosomenverkürzung. Zeitschr. Zellf.-mikr. Anat. $4: 338-364$.

Gates, R. R., and Rees, E. M. 1021. A cytological study of pollen development in Lactuca. Ann. Bot. 35: 365-398.

Gerassimova, H. 1935. The nature and causes of mutations II. Transmission of mutations arising in aged seeds: occurrence of homozygous dislocants among progeny of plants raised from aged seeds. Cytologia $6: 431-437$.

Heitz, E. 1929. Heterochromatin, Chromocentren, Chromomeren. Ber. Deu. bot. Ges. $47: 274-234$.

Hollingshead, L., and Babcock, E. B. 1930. Chromosomes and phylogeny in Crepis. Univ. Calif. Publ. Agr. Sci. 6:1-53.

Huskins, C. L. 1931. The origin of Spartina Townsendii. Genetica 12: 531-538.

Ishikawa, M. 1921. The chromosomes of Lactuca. Bot. Mag. (Tokyo) 35: (153). Japanese.

Jaretzky, R. 1925. Histologische und karyologische Studien an Polygonaceen. Jahrb. f. wiss. Bot. 69: 357-49u.

Kitamura, S. 1935. Ixerides Japonicae. Bot. Mag. (Tokyo) 49 : 280-297.

Levan, A. 1935. Cytological studies in Allium VI. The chromosome morphology of some diploid species of Allium. Hereditas $20: 289-330$.

Levitzky, G. A. 1931. The karyotype in systematics. Bull. Appl. Bot. Pl. Breed., (U.S.S.R.) $27: 220-240$.

Manton, I. 1932. Introduction to the general cytology of the Cruciferae. Ann. Bot. $46: 509-556$.

Marchal, E. 1920. Récherches sur les variations numériques des chromosomes dans la série végétale. Mém. Acad. Roy. Belg., II Series, I. IV, 8:1-108.

Müntzing, A. 1932. Apomictic and sexual seed formation in Poa. Hereditas 17: 131-154.

Nakai, T. 1920. Notulae ad plantas Japoniae et Koreae, XXIII. Bot. Mag. (Tokyo) 34: 141-158.

Navashin, M., and Gerassimova, H. 1935. The nature and causes of mutations I. On the nature and importance of chromosome mutations taking place in resting plant embryo due to their aging. Biologicheskii Zhurnal (Moscow) 4, ed. 4: 593-634.

Okabe, S. 1932. Parthenogenesis bei Ixeris dentata. Bot. Mag. (Tokyo) $46:(518)$. Japanese, with German summary.

Ono, H. kaj Satô, D. 1935. Intergenra hibridigo en Cichorieae, II. Hibridoj de Crepidiastrum lanceolatum var. latifolium kaj Paraixeris denticulata. Jap. Jour. Genet. 11 : 169-179.

Randolph, L. F. 1935. A new fixing fluid and a revised schedule for the paraffin method in plant cytology. Stain Technology. 10:95-96.

Sax, K. 1936. The experimental production of polyploidy. Jour. Arnold Arboretum $17: 153-159$.

Smith, F. H. 1934. The use of picric acid with the gram stain in plant cytology. Stain Technology. 9: 95-96.

Stebbins, G. L. Jr. 1937. Nomenclatorial changes in Lactuca and related genera. Jour. Bot. (London) (in press).

- 1936. Two new species of Lactuca from tropical Africa. Bull. Jard. Bot. de l'Etat, Bruxelles $14: 223-226$.

Stockwell, P. 1934. A stain for difficult plant material. Science, N. S. 80: 121-122.

Tahara, M. 1910. U̇ber die Zahl der Chromosomen von Crepis japonica Benth. Bot. Mag. (Tokyo) $24: 23-27$.

Tischler, G. 1936. Pflanzliche Chromosomen-Zahlen, Nachtr. 2, II. Tabulae Biol. Per. 6: $57-115$. 